\title{
WEAK TYPE ENDPOINT ESTIMATES FOR THE COMMUTATORS OF ROUGH SINGULAR INTEGRAL OPERATORS
}

\author{
Jiacheng Lan, XiangXing TaO and Guoen Hu
}

Abstract. Let $\Omega$ be homogeneous of degree zero and have mean value zero on the unit sphere $S^{n-1}, T_{\Omega}$ be the convolution singular integral operator with kernel $\frac{\Omega(x)}{\mid x^{n}}$. For $b \in \operatorname{BMO}\left(\mathbb{R}^{n}\right)$, let $T_{\Omega, b}$ be the commutator of $T_{\Omega}$. In this paper, by establishing suitable sparse dominations, the authors establish some weak type endpoint estimates of $L \log L$ type for $T_{\Omega, b}$ when $\Omega \in$ $L^{q}\left(S^{n-1}\right)$ for some $q \in(1, \infty]$.

Mathematics subject classification (2010): 42B20, 47A30.

Keywords and phrases: Commutator, singular integral operator, sparse operator, maximal operator.

\section{REFERENCES}

[1] J. Alvarez, R. J. BABgy, D. KURTZ AND C. PÉREZ, Weighted estimates for commutators of linear operators, Studia Math. 104 (1993), 195-209.

[2] A. P. CAlderón AND A. Zygmund, On the existence of certain singular integrals, Acta Math. 88 (1952), 85-139.

[3] A. P. Calderón And A. Zygmund, On singular integrals, Amer. J. Math. 78 (1956), 289-309.

[4] M. Christ AND J.-L. RUbio DE Francia, Weak type $(1,1)$ bounds for rough operators, II, Invent. Math. 93 (1988), 225-237.

[5] D. Chung, M. C. Pereyra, AND C. PÉRez, Sharp bounds for general commutators on weighted Lebesgue spaces, Trans. Amer. Math. Soc. 364 (2012), 1163-1177.

[6] R. R. COIFMAN, R. RochBERG AND G. WeIss, Factorization theorems for Hardy spaces in several variables, Ann. of Math., 103 (1976), 611-635.

[7] J. DUOANDIKOETXEA, Weighted norm inequalities for homogeneous singular integrals, Trans. Amer. Math. Soc. 336 (1993), 869-880.

[8] J. DuOAndikoetXea And J. L. Rubio De Francia, Maximal and singular integrals via Fourier transform estimates, Invent. Math. 84 (1986), 541-561.

[9] D. FAN AND Y. PAN, Singular integral operators with rough kernels supported by subvarieties, Amer. J. Math. 119 (1997), 799-839.

[10] L. Grafakos, Classical Fourier Analysis, GTM249, 2nd Edition, Springer, New York, 2008.

[11] L. GrafaKos, Modern Fourier Analysis, GTM250, 2nd Edition, Springer, New York, 2008.

[12] L. GRAFAKOS AND A. STEFANOV, $L^{p}$ bounds for singular integrals and maximal singular integrals with rough kernels, Indiana Univ. Math. J. 47 (1998), 455-469.

[13] G. HU, $L^{p}\left(\mathbb{R}^{n}\right)$ boundedness for the commutator of a homogeneous singular integral, Studia Math. 154 (2003), 13-47.

[14] G. HU, X. LAI AND Q. XUE, Weighted bounds for the compositions of rough singular integral operators, J. Geom. Anal., to appear; available at arXiv:1811.02878.

[15] T. Hytönen, M. T. LACEY AND C. PÉREZ, Sharp weighted bounds for the q-variation of singular integrals, Bull. Lond. Math. Soc. 45 (2013), 529-540.

[16] T. HYTÖNEn, L. RONCAL, AND O. TAPIOLA, Quantitative weighted estimates for rough homogeneous singular integrals, Israel J. Math. 218 (2017), 133-164.

[17] F. John, Quasi-isometric mappings, In: 1965 Seminari 1962/63 Anal. Alg. Geom. e Topol., 2, Ist. Naz. Alta Mat., Ediz. Cremonese, Rome, pp. 462-473. 
[18] A. K. LERnER, A weak type estimates for rough singular integrals, Rev. Mat. Iberoam. 35 (2019), 1583-1602.

[19] K. Li, C. PÉrez, IsReal P. Rivera-Rios And L. RonCAL, Weighted norm inequalities for rough singular integral operators, J. Geom. Anal. 29 (2019), 2526-2564.

[20] C. PÉREZ, I. P. Rivera-Rios, L. RonCAL, $A_{1}$ theory of weights for rough homogeneous singular integrals and commutators, Annali della Scuola normale superiore di Pisa, Classe di scienze. DOI: 10.2422/2036-2145.201608-011.

[21] C. PÉREZ, Endpoint estimates for commutators of singular integral operators, J. Funct. Anal. 128 (1995), 163-185.

[22] M. Rao And Z. Ren, Theory of Orlicz spaces, Monographs and Textbooks in Pure and Applied Mathematics, 146, Marcel Dekker Inc., New York, 1991.

[23] F. Ricci and G. Weiss, A characterization of $H^{1}\left(S^{n-1}\right)$, Proc. Sympos. Pure Math. of Amer. Math. Soc., (S. Wainger and G. Weiss eds), Vol. 35 I(1979), 289-294.

[24] I. P. RIVERA-Ríos, Improved $A_{1}-A_{\infty}$ and related estimate for commutators of rough singular integrals, Proc. Edinburgh Math. Soc. 61 (2018), 1069-1086.

[25] A. SEEgER, Singular integral operators with rough convolution kernels, J. Amer. Math. Soc. 9(1996), $95-105$.

[26] J. O. STRÖMBERG, Bounded mean oscillation with Orlicz, norms and duality of Hardy spaces, Indiana Univ. Math. J. 28 (1979), 511-544.

[27] A. M. VARGAS, Weighted weak type $(1,1)$ bounds for rough operators, J. London Math. Soc. 54 (1996), 297-310.

[28] M. J. WiLson, Weighted inequalities for the dyadic square function without dyadic $A_{\infty}$, Duke Math. J. 55 (1987), 19-50. 